\title{
DISCRIMINANT ANALYSIS AS A CONFIRMATORY FACTOR ANALYSIS TOOL: AN EXAMPLE FROM MATERIALISM MEASUREMENT
}

\author{
Dr. Saju Eapen Thomas \\ Department Chair - Marketing, City University College, \\ Ajman -CUCA, United Arab Emirates
}

\begin{abstract}
This research work is a confirmatory analysis using the data from the materialism measurement study published in 2016. Primary objective of this this study is to validate the ability of discriminant analysis, as a classification method that can predict the group membership of a newly sampled observation. The original study was based on a sample of 530 from three south Indian cities, and used a regression analysis based model that showed the existence of moderate to high levels of materialism among the respondents. Researcher, using CDA developed 'Canonical Discriminant Function Coefficients' and the predictor model. Further, using the group means of the predictor variables termed centroids, the study differentiates the respondents as low materialism and high materialism groups. Classification of the results, showed that CDA based classification of materialistic values had high level of matching, for both the low materialism and the high materialism groups, with those grouped using the regression analysis. This, inturn validates the ability of CDA to predict group membership based on materialism.
\end{abstract}

Keywords: Performance appraisal system, Cronbach Alpha, KMO and Bartlett test, Health care, Hyderabad

Cite this Article: Dr. Saju Eapen Thomas, Discriminant Analysis as a Confirmatory Factor Analysis Tool: An Example from Materialism Measurement, International Journal of Management (IJM), 10 (6), 2019, pp. 138-146.

http://iaeme.com/Home/issue/IJM?Volume $=10 \&$ Issue $=6$

\section{INTRODUCTION}

In this study, we are looking at the ability of discriminant analysis, as a classification method that can predict the group membership of a newly sampled observation (Sueyoshi, 2006). The SAS Institute of US defines canonical discriminant analysis (CDA) as a technique for dimension reduction, related to canonical correlation and principal component analysis (Cary, 1999). Thus, a canonical discriminant analysis derives a canonical variable from the given classification variable and several interval variables. It summarizes the between-class variation in much the same way that principal components summarize total variation. When one applies CDA to any given two or more groups of observations with measurements on several internal 
variables, it derives a linear combination of the variables. Such a derived linear combination will be one that has the highest possible multiple correlations with the group (Cary, 1999).

The research evidence leads us to the following inference regarding CDA. Given qualitative measurements of several variables of two or more groups of individuals, CDA helps to separate or discriminate two or more groups of individuals (Cruz-Castillo, et., al. 1994; Yuana, 2016). According to Cruz-Castillo et., al (1994), CDA identifies different linear functions of quantitative variables. CDA maximally separate two or more groups of individuals, while keeping variations within groups as small as possible. Sueyoshi (2006), wrote about a nonparametric DA approach that can provide a set of weights of a discriminant function, consequently yielding an evolution score for the determination of group membership.

This research work is a confirmatory analysis using the data from the materialism measurement study published in 2016. The original work used a regression-analysis based model. It showed the existence of moderate to high levels of materialism among the respondents (Thomas \& Wilson 2016). Presently, this discriminant analysis task is taken up to confirm the results obtained from the above study. The sample for the study is from the middle income, salaried class.

Middle-income groups or the middle class are mostly the salaried employees popularly known in India as the service classes. They have a regular income, which comes after tax deductions and also after the adjustments to take care of any loan-based liabilities. Hence, the middle-income groups will have a certain fixed disposable income to meet their various needs throughout the month. Hence, they are the most vulnerable group in terms of materialism and social pressure factors. Adopting a high consumption lifestyle can bring in financial strain much faster when compared to the rich lot.

\section{SAMPLE PROFILE AND DATA COLLECTION}

For data collection, we focused on the youth segment (20-40 age groups). They are the most gullible to advertising messages and more susceptible to upward social comparisons and peer group influence [Yovovich (1995)]. Moreover, in India, there has been a considerable increase in the salaries of this group in many new industry segments where professionally qualified or well-educated youth are finding employment. The organizations covered are mainly from sectors such as information technology (IT) and Information Technology Enabled Services (ITES), Advertising, Media, Entertainment and Telecom, Banking and Financial Sector, Consumer Goods Marketing and Sales.

The study focused on 530 samples collected from Kochi (210; 40\%), Bangalore (188; 35\%), and Hyderabad $(132 ; 25 \%)$ (International Council for Local Environment Initiatives ICLEI report, 2011; Mitra, 2008). As mentioned earlier, all respondents were working in the management cadre of leading organizations. $356(67 \%)$ of the respondents were male, and 174 were females. $57.2 \%$ of them were married, and $62 \%$ of the married had their spouses also working. As envisaged in the study design to focus more on youth, $56.8 \%$ of the sample belonged to the $20-30$ age group, and $31.5 \%$ belonged to the $30-40$ age group. Only $11.7 \%$ belonged to the older groups ( $6.9 \%$ in the $40-50$ age group and $4.8 \%$ in the $50-60$ age group). $65 \%$ of the target group had professional qualifications, and among the rest, $14 \%$ were postgraduate degree holders, and $21 \%$ were just graduates. Only $19 \%$ of the respondents belonged to senior-level positions, while $81 \%$ of the respondents had jobs at the middle $(53.5 \%)$ and junior levels (27.5\%) (Thomas \& Wilson, 2016).

The study uses three different scales to measure the different constructs, which are crucial to the conceptualizations proposed. Scaling is the process of measuring quantitative aspects of subjective or abstract concepts. It is the method of assigning numbers or symbols to some 
attitudes of an object (Kumar, 2005). The researcher developed a continuum based scale to locate the measured objects.

\section{REGRESSION ANALYSIS}

In consideration of these findings, an attempt was made to generate a model by linking independent variables like Attitude to Television, Peer Pressure, Social Comparison, and Attitude to Debt to the independent variable Social Pressure through multiple regression analysis. The researcher furnishes the results in tables 1a, 1b, and 1.11c (Thomas \& Wilson, 2016).

Table 1a: Multiple Regression Analysis of Social Pressure and Social Pressure Factors - Model Summary

\begin{tabular}{|c|c|c|c|c|}
\hline Model & R & R Square & Adjusted R Square & $\begin{array}{c}\text { Std. Error of the } \\
\text { Estimate }\end{array}$ \\
\hline 1 & $0.706^{\mathrm{a}}$ & 0.498 & 0.494 & 2.24441 \\
\hline a. Predictors: (Constant), Attitude to credit, Attitude to TV, Social Comparison, Peer Pressure \\
\hline
\end{tabular}

Table 1b: Multiple Regression Analysis of Social Pressure and Social Pressure Factors - ANOVA a, b

\begin{tabular}{|c|c|c|c|c|c|c|}
\hline \multicolumn{2}{|c|}{ Model } & Sum of Squares & Df & Mean Square & F & Sig. \\
\hline \multirow{3}{*}{1} & Regression & 2566.026 & 4 & 641.506 & 127.350 & $.000^{\mathrm{a}}$ \\
\cline { 2 - 8 } & Residual & 2584.169 & 513 & 5.037 & & \\
\cline { 2 - 8 } & Total & 5150.195 & 517 & & & \\
\hline
\end{tabular}

a. Predictors: (Constant), Attitude to credit, Attitude to TV, Social Comparison, Peer Pressure

b. Dependent Variable: Social Pressure

The model is capable of explaining $50 \%$ of the variations in the dependent variable due to the changes in the independent variables. The regression was found to be significant with $\mathrm{F}$ $=127.35, \mathrm{df}=4, \mathrm{p}<0.05$. The sum of squares of the regression (2566.026) is the part that could be explained by the regression equation out of the total sum of squares (5150.195).

Table 1c: Multiple Regression Analysis of Social Pressure and Social Pressure Factors -Coefficients

\begin{tabular}{|c|c|c|c|c|c|c|}
\hline & \multirow[t]{2}{*}{ Model } & \multicolumn{2}{|c|}{$\begin{array}{l}\text { Un-standardized } \\
\text { Coefficients }\end{array}$} & \multirow{2}{*}{$\begin{array}{c}\text { Standardized } \\
\text { Coefficients }\end{array}$} & \multirow[t]{2}{*}{$\mathbf{T}$} & \multirow[t]{2}{*}{ Sig. } \\
\hline & & B & Std. Error & & & \\
\hline \multirow{5}{*}{1} & (Constant) & 1.149 & .474 & & 2.422 & .016 \\
\hline & Attitude to TV & .520 & .076 & .233 & 6.807 & .000 \\
\hline & Peer Pressure & .236 & .037 & .260 & 6.348 & .000 \\
\hline & Social Comparison & .330 & .047 & .290 & 7.078 & .000 \\
\hline & Attitude to credit & .220 & .041 & .181 & 5.367 & .000 \\
\hline
\end{tabular}

Hence social pressure can be predicted by the equation: 
Social Pressure $=1.149+(0.520$ Attitude to TV $)+(0.236$ Peer Pressure $)+(0.330$ Social Comparison $)+(0.220$ Attitude to debt $)$.

The constant in the equation and the coefficients are significant $(p<0.05)$.

Scatterplot

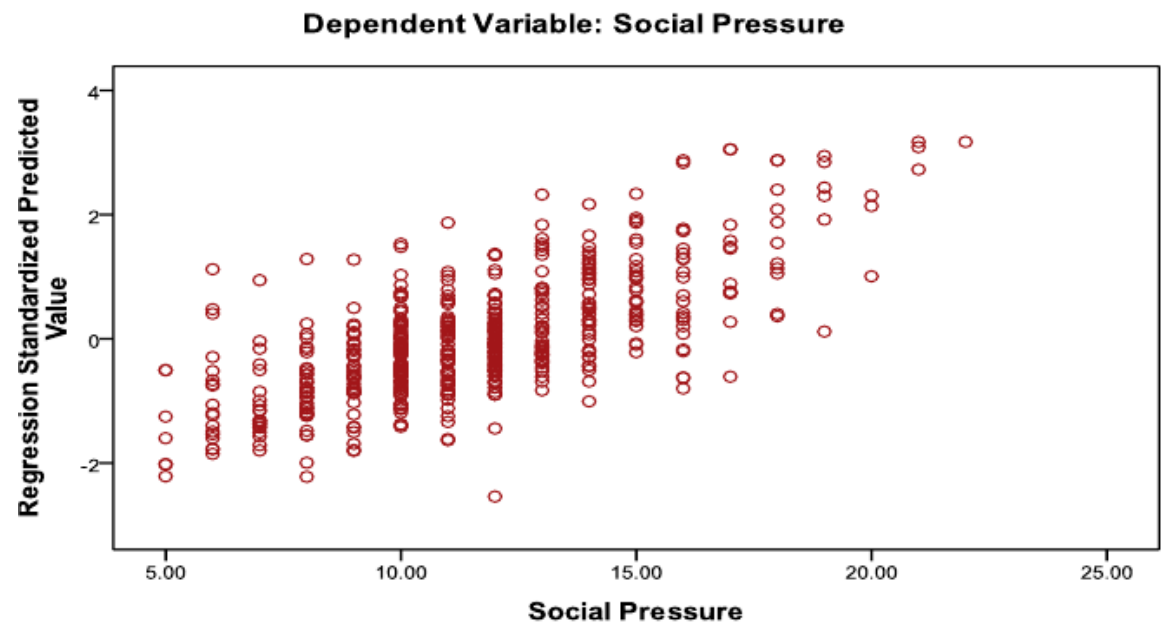

Figure 1 Scatter Plot of Multiple Regression-Based Predicted Value for Social Pressures and Actual Social Pressure Measures

In consideration of these findings, an attempt was made to generate a model by linking independent variables like Attitude to Television, Peer Pressure, Social Comparison, and Attitude to Debt to the independent variable Social Pressure through multiple regression analysis. The researcher furnishes the results in table $1.1 \mathrm{a}, 1.1 \mathrm{~b}$ and $1.1 \mathrm{c}$.

First-Stage regression analysis showed that these four contributors could explain $50 \%$ variations in social pressure. The regression model given below indicates that social pressure could be predicted by the equation: Social Pressure $=1.149+(0.520$ Attitude to TV $)+(0.236$ Peer Pressure $)+(0.330$ Social Comparison $)+(0.220$ Attitude to Debt $)$. The researcher compares the model predicted values with actual measured values of social pressure and the scatter plots showed large significant linear overlap.

Based on these findings, one can draw inferences that attitude to television, peer pressure, social comparisons, and attitude to debt causes social pressure in individuals. The second stage of regression analysis attempts to establish a predictive model between social pressure and materialism. The study shows that social pressure alone could predict $21.5 \%$ variation in materialism and that the equation can predict materialism: Material values $=36.014+1.37$ (Social Pressure). Once again, the research work compares the regression predicted values compared with the measured values of materialism, and it confirmed the existence of linear association as predicted through the model.

Combining the output from these two regression exercises, the social pressure-materialism model, as shown in fig 6.19, was developed. Accordingly, materialism can be predicted by the equation: Material values $=37.59+0.72$ (Attitude to TV) +0.32 (Peer Pressure) +0.45 (Social Comparison) +0.30 (Attitude to Debt). This output indicates that the combined effect of social pressure and its contributing factors predicts materialism. 


\section{CANONICAL DISCRIMINANT FUNCTIONS - PREDICTING MATERIALISM}

The model developed through this study is tested using canonical discriminant analysis. The author tested the validity of the model with a confirmatory factor analysis using structural equation modeling. The researcher describes the activities required for the proposed work.

We used discriminant analysis to model the value of a dependent variable based on its relationship to one or more predictors. The discriminant analysis builds a predictive model for group membership. This model comprises of a discriminant function (a set of discriminant functions) based on linear combinations of the predictor variables. Predictor variables included are those variables that provide the best discrimination between the groups.

Table 2.a: Canonical Discriminant Function - Eigen Values

\begin{tabular}{|c|c|c|c|c|}
\hline \multicolumn{5}{|c|}{ Eigen values } \\
\hline Function & Eigen value & \% of Variance & Cumulative \% & $\begin{array}{c}\text { Canonical } \\
\text { Correlation }\end{array}$ \\
\hline 1 & $.291^{\text {a }}$ & 100.0 & 100.0 & .475 \\
\hline a. First 1 Canonical Discriminant functions were used in the analysis. \\
\hline
\end{tabular}

The Eigenvalue (0.291) indicates the proportion of variance explained. In this model, the researcher takes only one canonical function is taken, and thus the percentage of variance is $100 \%$. The canonical correlation $(0.475)$ is the correlation between the discriminant scores and the levels of the dependent variable which was found to be positively correlated.

Table 2.b: Canonical Discriminant Function - Wilk’s Lambda

\begin{tabular}{|c|c|c|c|c|}
\hline \multicolumn{5}{|c|}{ Wilks' Lambda } \\
\hline $\begin{array}{c}\text { Test of } \\
\text { Function(s) }\end{array}$ & Wilks' Lambda & Chi-square & Df & Sig. \\
\hline 1 & .775 & 131.126 & 5 & .000 \\
\hline
\end{tabular}

Wilks' Lambda is the ratio of within-groups sums of squares to the total sums of squares. Differences do not explain the proportion of the total variance in the discriminant scores among groups. Here Wilks Lambda was found to be $0.775 ; \mathrm{p}<0.01$, and it indicates that the group means do not appear to differ.

The 'Canonical Discriminant Function Coefficients' indicate the un-standardized scores concerning the independent variables. It is the list of coefficients of the un-standardized discriminant equation.

Table 2.c: Standardized Canonical Discriminant Function - Coefficients

\begin{tabular}{|l|c|}
\hline Social Pressure & .388 \\
\hline Attitude to TV & .058 \\
\hline Peer Pressure & .144 \\
\hline Social Comparison & .522 \\
\hline Attitude to credit & .212 \\
\hline
\end{tabular}

Here the predictor equation is as given below: 
Materialism $=(0.388$ Social Pressure $)+(0.058$ Attitude to Television $)+(0.144$ Peer Pressure $)+(0.522$ Social Comparison $)+(0.212$ Attitude to Debt $)$

Those coefficients with large absolute values correspond to the variables with greater discriminating ability. Another way of interpreting discriminant analysis results is to describe each group in terms of its profile, using the group means of the predictor variables. These group means are called centroids. Functions at group centroid indicate the average discriminant score in the two groups.

Table 2.d: Functions at Group Centroids

\begin{tabular}{|c|c|}
\hline \multirow{2}{*}{ Materialism Level } & Function \\
\cline { 2 - 2 } & $\mathbf{1}$ \\
\hline Low Materialism & -.553 \\
\hline High Materialism & .524 \\
\hline Un-standardized canonical discriminant functions evaluated at group means \\
\hline
\end{tabular}

The researcher interprets that people with low materialism will have a mean value of -0.553 , while people with high materialism will have a mean value of 0.524 . Cases with scores closer to a centroid predict belonging to that group. Fig 6.20 below is a pictorial representation of the centroids.
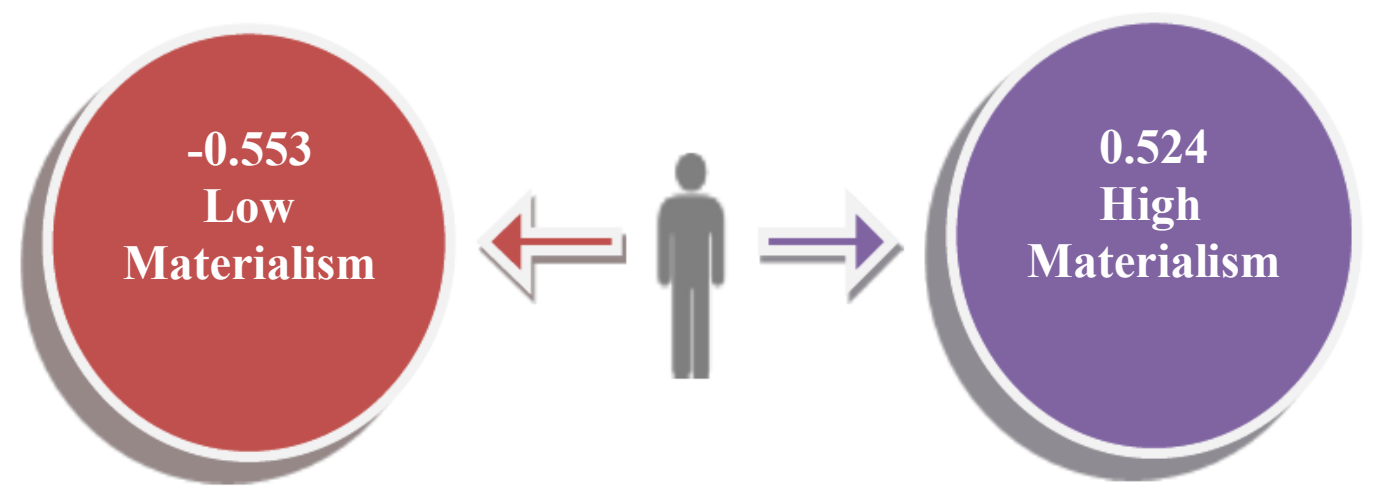

Figure 2: Group Centroids - Low Materialism and High Materialism Groups

Finally, there is the classification phase. The classification table is simply a table in which the rows are the observed categories of the dependent, and the columns are the predicted categories. The discriminant function classified $70 \%$ of the original grouped cases correctly. 
Discriminant Analysis as a Confirmatory Factor Analysis Tool: An Example from Materialism Measurement

Table 3: Classification of Results (Original versus Predicted)

\begin{tabular}{|c|c|c|c|c|c|}
\hline \multicolumn{5}{|c|}{ Classification Results } \\
\hline \multirow{3}{*}{ Original } & \multirow{3}{*}{$\begin{array}{c}\text { Materialism } \\
\text { Level }\end{array}$} & \multicolumn{2}{c|}{ Predicted Group Membership } & \multirow{2}{*}{ Total } \\
\cline { 3 - 6 } & \multirow{3}{*}{ Count } & Low Materialism & High Materialism & \multirow{2}{*}{252} \\
\cline { 3 - 6 } & & High Materialism & 91 & 65 & 266 \\
\cline { 3 - 6 } & & Total & 278 & $\mathbf{1 7 5}$ & \\
\cline { 3 - 6 } & \multirow{3}{*}{$\%$} & Low Materialism & $\mathbf{7 4 . 2}$ & 240 & 100.0 \\
\cline { 3 - 6 } & & High Materialism & 34.2 & $\mathbf{6 5 . 8}$ & 100.0 \\
\hline
\end{tabular}

a. $\quad 69.9 \%$ of the original grouped cases correctly classified.

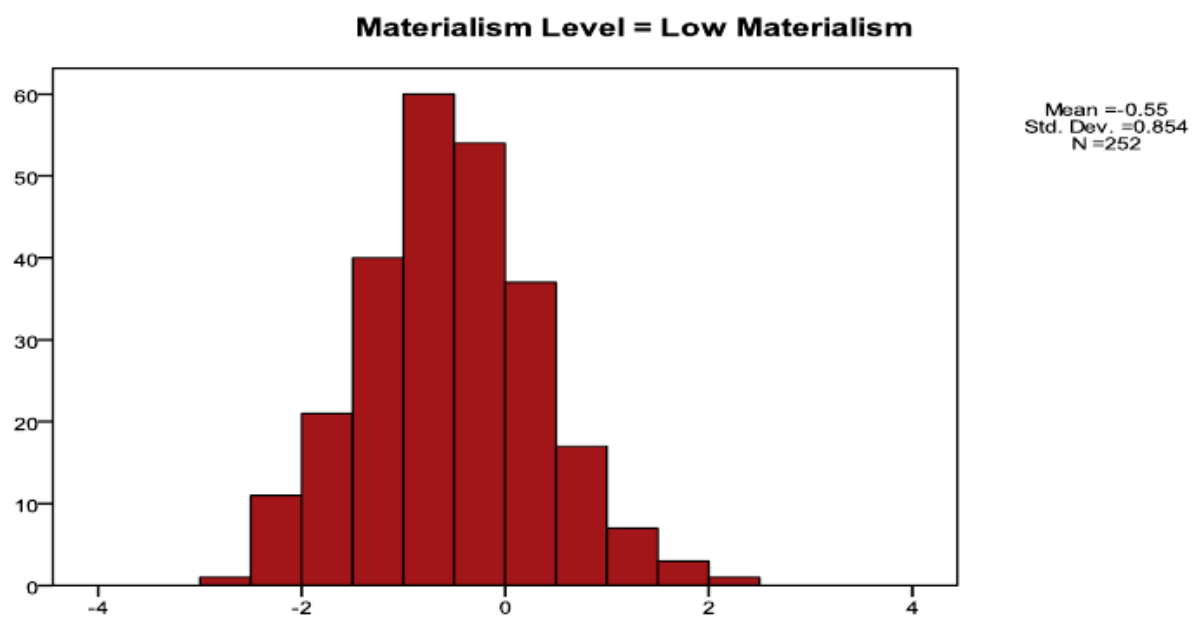

Figure 3a: Histogram of low materialism Group

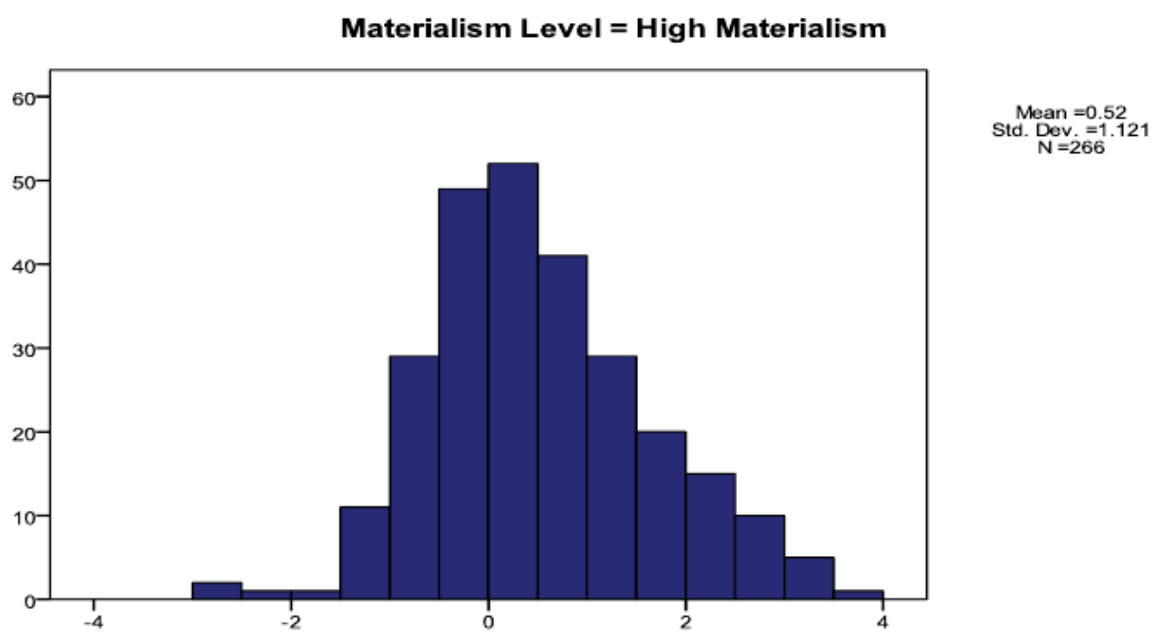

Figure 3b: Histogram of High Materialism Group

Fig. 3.a, and Fig. 3.b respectively represent the histograms of materialism levels for the low materialism group and high materialism group segregated by the discriminant function. From the histogram plots, we can note that the distributions are almost normal. 


\section{CONCLUSION}

Thus, the study can exhibit the ability of discriminant analysis to classify and predict the group membership of any sample. Hence, it is beyond doubt that CDA is a dimension reduction technique. The multistage regression analysis had established the relationship between materialism and social pressure factors such as attitude to TV, peer pressure, social comparison and attitude to debt. This exercise proved the existence of materialism among the sample. In the above exercise, CDA models the value of materialism based on the predictive equation for social pressure with all its subfactors. Table-2c shows the predictive model generated.

Based on the predictor equation, the researcher classifies the respondents into two groups one of the respondents with low materialism and another group of those having high materialism. For interpreting discriminant analysis, the researcher works out the group means or centroids as shown in Table-2d. Classification of the results, presented in table-3, shows that CDA based classification of materialistic values had $74.2 \%$ matching for low materialism grouped using the regression analysis. For the high materialism group, there was $65.8 \%$ matching. This, in-turn proves the ability of CDA to predict group membership based on materialism.

\section{REFERENCES}

[1] Bearden, W. O, Netemeyer, R. G. \& Teel. J. E, "Measurement of Consumer Susceptibility to Interpersonal Influence"; Journal of Consumer Research; v.15 (4); 1989, p. 473-481.

[2] Sueyoshi, Toshiyuki, DEA Discriminant Analysis: Methodological comparison among Eight Discriminant Analysis Approaches; European Journal of Operations Research; Feb 2006; Vol.169, Issue 1; 2006, p. 247-272.

[3] Yuanan, Yubo, Chenglong M. A. and Dong Mei P. U, A Novel Discriminant Minimum Class Locality Preserving Canonical Correlational Analysis and Its Applcations; Journal of Industrial and Management Optimization; Vol.12 (1); Jan 2016; p.251-268.

[4] Cary, N.C, SAS Institute Inc. USA; www.usdoc.sas.com downloaded on 2/9/2019, 1999

[5] Cruz-Castillo, J.G., Ganeshanandam, S., Mackay, B. R., Laws, G. S., Lawoko, C.R.O. and Wooley, D. J.; Applications of Canonical Discriminant Analysis in Horticultural Research; Horticultural Science; Vol. 29 (10); Oct 1994; p.1115-1119.

[6] ICLEI - Report www.iclei.org, 2011

[7] Kasser, T., Ryan, R.M., Couchman, C.E. \& Sheldon, K.M, "Materialistic Values: Their Causes \& Consequences"; in T. Kasser \& A.D.Kanner (Eds.); Psychology \& Consumer Culture: The Struggle for Good Life in A Materialistic World; Washington D.C.:American Psychological Association; 2004, P.11-28.

[8] Dr. D.K. Ghosh and Shweta S. Kulshrestha, Comparison of Employee Branding Through Discriminant Analysis. International Journal of Management, 7(7), 2016, pp. 395-405.

[9] Kumar, Ranjith, "Research Methodology - A Step-by-Step Guide for Beginners"; 2e, Pearson Education (Singapore) Pte. Ltd., New Delhi, 2005

[10] Leah, S. E. G., Webley, P. \& Walker, C. M, "Psychological Factors in Consumer Debt: Money management, Economic Socialization and Credit Use"; Journal of Economic Psychology; v. 16, 1995, p. 681-701. 
Discriminant Analysis as a Confirmatory Factor Analysis Tool: An Example from Materialism Measurement

[11] Dr.V. Sakthirama, Dr. R.Venkatram and Dr.S.D.Sivakumar, Factors Affecting the Regularity of Purchase of Organic Tea - An Application Discriminant Analysis, International Journal of Management (IJM), Volume 4, Issue 5, September - October (2013)

[12] Lennox, R. D. \& Wolfe, R. N, "Revision of the Self-Monitoring Scale"; Journal of Personality \& Social Psychology; v. 46, 1984, p. 461-471.

[13] Mitra, Abhijit, "The Freedom to Choose"; (The OLM - Indicus Analytics - Spirit of Freedom Survey), Outlook Money; 27 August 2008, P 17-24.

[14] Dr. G. Somasekhar, Dr. S. Ahamed Basha and Dr. Varadarajan Rangarajan, Predication of Shoppers' Perceptual Differences in Traditional Retail Stores: An Application of Discriminant Analysis, International Journal of Mechanical Engineering and Technology, 9(10), 2018, pp. 1326-1335.

[15] Richins, M. L. \& Dawson, S, "Consumer Values Orientation for Materialism: Scale Development \& Validation”; Journal of Consumer Research; v. 19, 1992, p.303-316.

[16] Richins, M. L. \& Dawson, S, "Consumer Values Orientation for Materialism: Scale Development \& Validation"; Journal of Consumer Research; v. 19, 1992, p.303-316.

[17] Rossiter, J. R, "Reliability of a Short Test Measuring Children's Attitude toward TV Commercials"; Journal of Consumer Research; v. 3 (4), 1977, p.179-184.

[18] Yovovich, B. G, "Youth Market Going Truly Global"; Advertising Age; March 27, 1995, p.10.

[19] Thomas and Wilson, "The Role of Social Pressure as a Moderator of Materialism"; The IUP Journal of Management Research, (Icfai University Press); Vol. XV (2); April, 2016; p.732. 